\title{
Bacillus anthracis secretome time course under host-simulated conditions and identification of immunogenic proteins
} Alexander Walz*1, Cesar V Mujer ${ }^{1,4}$, Joseph P Connolly ${ }^{1}$, Tim Alefantis ${ }^{1}$, Ryan Chafin1, Clarissa Dake ${ }^{1}$, Jessica Whittington'1, Srikanta P Kumar², Akbar S Khan ${ }^{3}$ and Vito G DelVecchio ${ }^{1}$

\author{
Address: ${ }^{1}$ Vital Probes, Inc., 1300 Old Plank Road, Mayfield, PA 18433, USA, ${ }^{2}$ BAE Systems Inc., 164 Totowa Road, Wayne, NJ 07474, USA, \\ ${ }^{3}$ Chemical and Biological Defense Directorate, Defense Threat Reduction Agency, 6801 Telegraph Road, Alexandria, VA, USA and ${ }^{4}$ Calvert \\ Laboratories, Inc., Scott Technology Park, 100 Discovery Drive, Olyphant, PA 18447, USA \\ Email: Alexander Walz* - awalz@vitalprobes.com; CesarV Mujer - cesar.mujer@calvertlabs.com; \\ Joseph P Connolly - jconnolly@vitalprobes.com; Tim Alefantis - talefantis@vitalprobes.com; Ryan Chafin - rchafin@vitalprobes.co; \\ Clarissa Dake - cdake@vitalprobes.com; Jessica Whittington - jwhittington@vitalprobes.com; \\ Srikanta P Kumar - srikanta.kumar@baesystems.co; Akbar S Khan - akbar.khan@whs.mil; Vito G DelVecchio - vdelvecchio@vitalprobes.com \\ * Corresponding author
}

Published: 27 July 2007

Proteome Science 2007, 5:II doi:10.1 I86/1477-5956-5-II
Received: 9 April 2007

Accepted: 27 July 2007

This article is available from: http://www.proteomesci.com/content/5/I/II

C 2007 Walz et al; licensee BioMed Central Ltd.

This is an Open Access article distributed under the terms of the Creative Commons Attribution License (http://creativecommons.org/licenses/by/2.0), which permits unrestricted use, distribution, and reproduction in any medium, provided the original work is properly cited.

\begin{abstract}
Background: The secretion time course of Bacillus anthracis strain RA3R ( $\mathrm{PXOI} / \mathrm{pXO2}$ ) during early, mid, and late log phase were investigated under conditions that simulate those encountered in the host. All of the identified proteins were analyzed by different software algorithms to characterize their predicted mode of secretion and cellular localization. In addition, immunogenic proteins were identified using sera from humans with cutaneous anthrax.

Results: A total of 275 extracellular proteins were identified by a combination of LC MS/MS and MALDI-TOF MS. All of the identified proteins were analyzed by SignalP, SecretomeP, PSORT, LipoP, TMHMM, and PROSITE to characterize their predicted mode of secretion, cellular localization, and protein domains. Fifty-three proteins were predicted by SignalP to harbor the cleavable $\mathrm{N}$-terminal signal peptides and were therefore secreted via the classical Sec pathway. Twenty-three proteins were predicted by SecretomeP for secretion by the alternative Sec pathway characterized by the lack of typical export signal. In contrast to SignalP and SecretomeP predictions, PSORT predicted $17 \mid$ extracellular proteins, 7 cell wall-associated proteins, and 6 cytoplasmic proteins. Moreover, $5 \mathrm{I}$ proteins were predicted by LipoP to contain putative Sec signal peptides ( 38 have Spl sites), lipoprotein signal peptides ( 13 have Spll sites), and $\mathrm{N}$-terminal membrane helices ( 9 have transmembrane helices). The TMHMM algorithm predicted 25 membrane-associated proteins with one to ten transmembrane helices.

Immunogenic proteins were also identified using sera from patients who have recovered from anthrax. The charge variants ( 83 and $63 \mathrm{kDa}$ ) of protective antigen (PA) were the most immunodominant secreted antigens, followed by charge variants of enolase and transketolase.

Conclusion: This is the first description of the time course of protein secretion for the pathogen Bacillus anthracis. Time course studies of protein secretion and accumulation may be relevant in elucidation of the progression of pathogenicity, identification of therapeutics and diagnostic markers, and vaccine development. This study also adds to the continuously growing list of identified Bacillus anthracis secretome proteins.
\end{abstract}




\section{Background}

Bacillus anthracis is a Gram-positive spore-forming bacterium that is the etiologic agent of anthrax [1]. During the course of infection, the virulent spores germinate to become vegetative cells. The bacterium secretes two major virulence factors, the bipartite edema and lethal toxins that are encoded by plasmid pXO1 [1-3]. The common component of both toxins is the protective antigen (PA) which is not toxic by itself. PA binds a specific receptor on the host cells and translocates the edema factor (EF) and lethal factor (LF) inside the cells where they exert their damaging action. Transcription of the genes coding for these virulence factors has been shown to be coordinately induced by bicarbonate- $\mathrm{CO}_{2}$. High $\mathrm{CO}_{2}$ tension is believed to simulate conditions encountered within the host [4]. In addition, the effect of temperature has been shown to be important for toxin production but not for production of antiphagocytic capsule, whose synthesis is encoded by genes on plasmid pXO2 [5]. Thus, when $B$. anthracis is cultured at $37^{\circ} \mathrm{C}$ in a bicarbonate-containing minimal medium, toxin production is enhanced.

The composition and identification of B. anthracis extracellular proteins (secretome) has been the subject of recent proteomic studies [6-9]. In B. cereus, a close relative of $B$. anthracis, most of these secreted proteins include collagenases, phospholipases, hemolysins, proteases, and enterotoxins that are positively regulated by plcR [10]. However, a non-sense mutation inactivates a homolog of this gene in $B$. anthracis resulting in a significant reduction of these secreted proteins $[1,11,12]$. Using 2-DE and MALDI-TOF MS, Chitlaru et al. [6] have identified 64 extracellular proteins in a virulent $B$. anthracis strain, of which 50 exhibit export signal peptides. Thirty-one of these secreted proteins harbor features that are characteristic of virulence determinants suggesting that in addition to the "classic" lethal and edema toxins, a large number of proteins may be essential for $B$. anthracis virulence [6]. Additionally, in minimal medium under high $\mathrm{CO}_{2}$ tension, the presence of the plasmids led to the enhanced secretion of 12 chromosome-encoded and 5 pXO1 encoded proteins. Ten of the chromosome-encoded proteins could not be detected in the absence of the plasmids. These results suggest distinct plasmid and chromosome $\mathrm{CO}_{2}$-dependent crosstalk mechanisms that modulate extracellular proteolytic activities. Likewise, Antelmann et al. [7] have identified 64 extracellular proteins in the nonvirulent $B$. anthracis strain UM23C1-2 (pXO1\%/pXO2-), 29 of which were predicted to be secreted. The remainder of the extracellular proteins were predicted to be associated with the cell wall or the cytosol. Based on the nature of $B$. anthracis secretome, it was suggested that this organism is adapted to life in a protein-rich environment due to the presence of a variety of proteases, peptidases, peptidebinding proteins, as well as enzymes required for the metabolism of amino acids. It was also proposed that these secreted proteases and peptidases could be useful targets for the development of improved vaccines.

In another study, Gohar et al. [8] compared the fully cured $B$. anthracis extracellular proteomes to two other members of the B. cereus group, $B$. cereus and B. thuringiensis, that were also cured of their plasmids. The secretomes of the three species included both cell wall and cytosolic proteins that are similar in all three species. However, whereas the extracellular proteins of B. cereus and B. thuringiensis contained a large number of secreted proteins such as degradative enzymes and toxins, those of $B$. anthracis contained only one secreted protein, a metalloprotease InhA1. These results are in contrast to those reported by Chitlaru et al. [6] and Antelmann et al. [7] where 31 and 29 secreted proteins were identified in the culture filtrate of fully cured $B$. anthracis cells, respectively. Using minimal medium under high $\mathrm{CO}_{2}$ tension, a comparative analysis of the extracellular proteomes of three isogenic strains of $B$. anthracis that differed solely in their plasmid content was conducted by Lamonica et al. [9]. In this study, the use of SignalP for the prediction of cellular function and location of each protein indicated that most of the identified proteins were either cell wall-associated or cytoplasmic in the fully cured strain, RA3:00.

The present study characterized the time course of protein secretion and accumulation in the culture of $B$. anthracis strain RA3R (pXO1+/pXO2-). Secretion patterns at the different time points are due not only to differentially expressed proteins at various phases of exponential growth, but also to the accumulation of proteins in the culture and their stability therein. Particular focus was placed on the analysis of protein secretion during the exponential growth phase to preclude the identification of proteins that may have been caused by bacterial lysis. In addition, computer assisted comparative analysis using 2D Phoretix of the cytosol with the secretome at16 hr under induced conditions was performed. LC MS/MS was used as a complementary tool in identifying proteins that were not amenable to MALDI-TOF MS, significantly increasing the number of identified secreted proteins. The data from this analysis add to the growing list of identified proteins in the secretome database of $B$. anthracis and help in further identifying key pathways associated with virulence. Furthermore, immunogenic proteins, or the immunome, of the secretome were identified using sera from human patients infected with cutaneous anthrax. Identification of these immunodominant antigens is essential for development of more efficacious and safer vaccines against anthrax. 


\section{Results}

Time course of protein secretion

The extracellular proteomes of $B$. anthracis strain RA3R were analyzed at three time points during the exponential growth phase, i.e., early ( $6 \mathrm{hr})$, mid (10 hr) and late log (16 hr) under induced, host-simulated conditions (Fig. 1). 2D Phoretix computer-assisted analysis of 2-DE average gels revealed that the number of protein spots increased from 54 spots at $6 \mathrm{hr}$ to 308 spots at $10 \mathrm{hr}$ and to 536 spots at $16 \mathrm{hr}$. (Figs. 2A-C). In contrast, the number of protein spots at $16 \mathrm{hr}$ under uninduced condition (Fig. 3) is only 178 or $33 \%$ of the total number under induced condition (Fig. 4). The S-layer proteins Sap (surface array protein) and EA1 (extractable antigen 1), PA, and enolase were the predominant proteins that increased in secretion (Fig. 5). Other highly expressed proteins include alkyl hydroperoxide reductase, chaperonin $60 \mathrm{kDa}$, phosphoglycerate isomerase, sulfatase, manganese superoxide dismutase, and a zinc-binding lipoprotein.

\section{Extracellular proteins}

A total of 275 proteins were identified in the extracellular proteome by a combination of MALDI-TOF MS and LC MS/MS (Fig. 3/4, additional file 1). MALDI-TOF MS analysis has identified 52 proteins of which 47 were also identified by LC MS/MS analysis. In contrast, 270 proteins were identified by LC MS/MS. This indicates that the combined use of MALDI-TOF MS and LC MS/MS has significantly increased the total number of identified proteins in the extracellular proteome, which has also been observed in the analysis of the proteome of other bacteria such as Mycobacterium tuberculosis [13] and Brucella abortus [14].

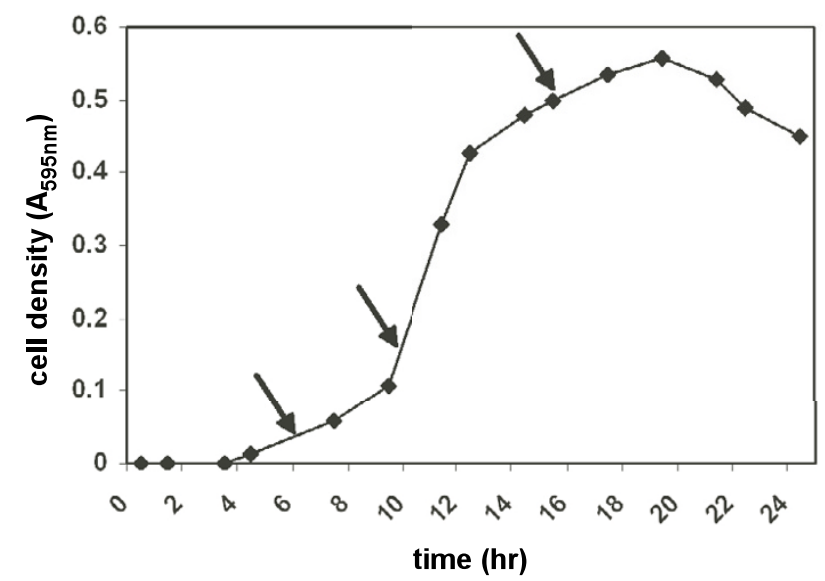

\section{Figure I}

Growth curve for B. anthracis strain RA3R ( $\mathrm{pXO}$ I $^{+} / \mathrm{p} X \mathrm{O}^{-}$) in $R$ medium under host simulated conditions (induced).

Secretome proteins were harvested at time points 6,10 , and $16 \mathrm{hrs}$ as indicated by the arrows.

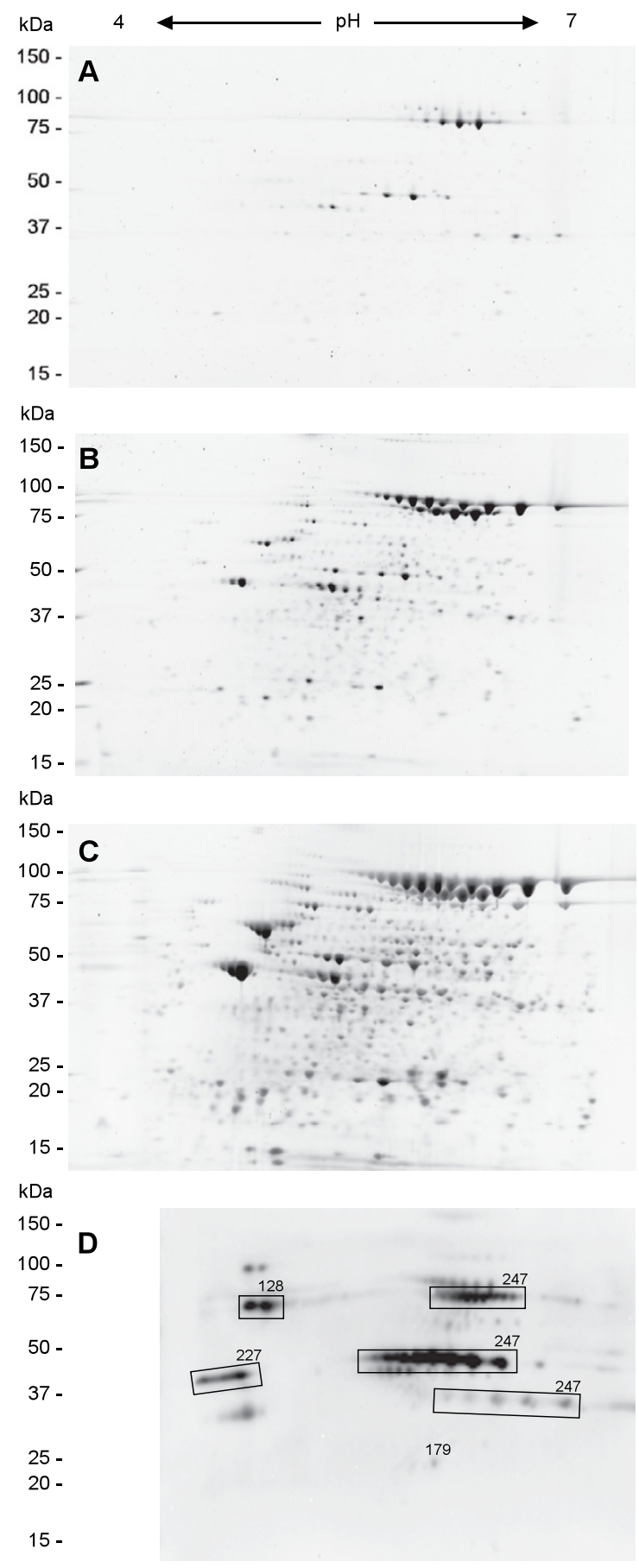

\section{Figure 2}

2-DE gel images of SYPRO Ruby-stained secretome proteins of toxigenic, non-encapsulated $B$. anthracis strain RA3R

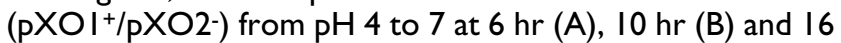
$\mathrm{hr}(\mathrm{C})$ after inoculation under conditions that simulate those found inside the host (induced), and (D) Western blot analysis of immunogenic extracellular proteins at $16 \mathrm{hr}$ using sera from patients infected with cutaneous anthrax. Spot numbers refer to additional file I. 


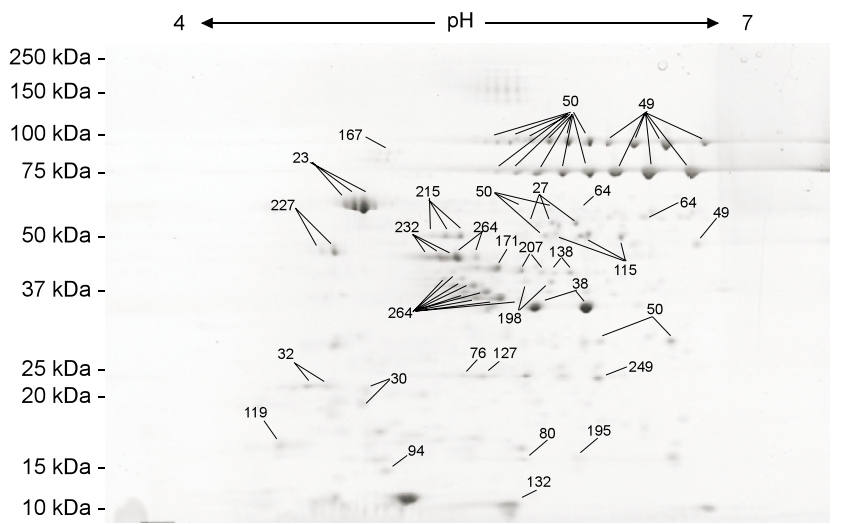

Figure 3

Annotated 2-DE gel image of SYPRO Ruby-stained secretome proteins of $B$. anthracis strain RA3R ( $\left.\mathrm{pXO} 1^{+} / \mathrm{pXO} 2^{-}\right)$at $16 \mathrm{hr}$ after inoculation under laboratory conditions (uninduced). Spot numbers refer to additional file I.

The $B$. anthracis secretome proteins were also grouped into major cellular functions (Fig. 6). Half of all identified secretome proteins are involved in energy metabolism $(17.8 \%)$, protein synthesis $(10.9 \%)$, cellular structure $(8.7 \%)$, or are hypothetical $(13 \%)$. This distribution is significantly different from role category predictions of all genes theoretically encoded by $B$. anthracis. Some groups were overrepresented or underrepresented relative to the theoretical total $B$. anthracis proteome, where energy metabolism accounts for $5.2 \%$, protein synthesis is $2.4 \%$, cellular structure is $7.1 \%$, and hypothetical proteins are $40.6 \%$ of all cellular proteins. The role category predictions of $B$. anthracis were obtained from The Institute for Genomic Research website [15].

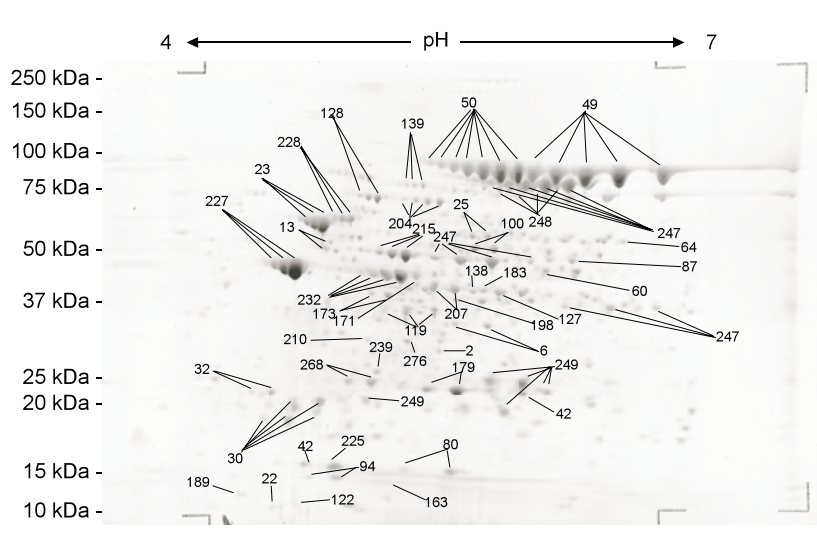

Figure 4

Annotated 2-DE gel image of SYPRO Ruby-stained secretome proteins of $B$. anthracis strain RA3R ( $\left.\mathrm{pXO} 1^{+} / \mathrm{pXO} 2^{-}\right)$at $16 \mathrm{hr}$ after inoculation under host simulated conditions (induced). Spot numbers refer to additional file I.

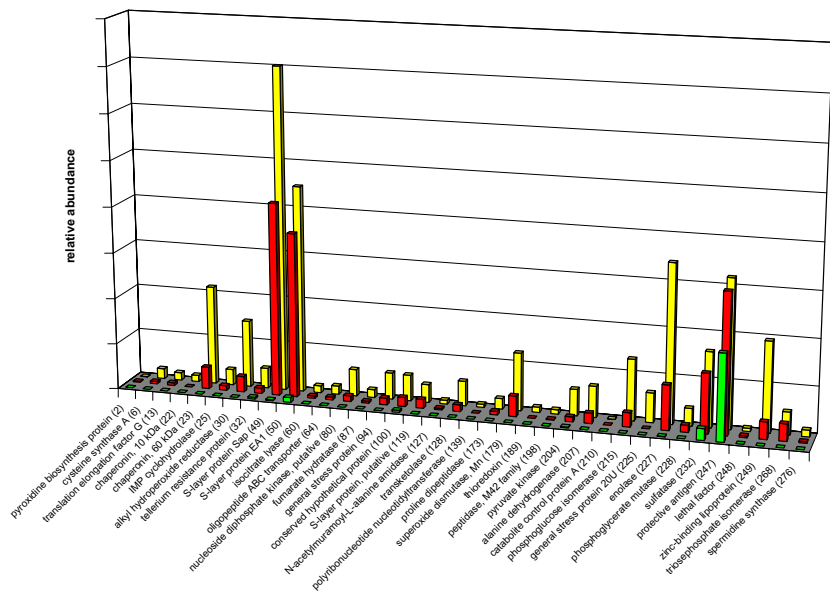

Figure 5

Relative protein expression of differentially expressed extracellular proteins of $B$. anthracis strain RA3R ( $\left.\mathrm{pXO} \mathrm{I}^{+/} \mathrm{pXO2}-2^{-}\right)$ during exponential growth at $6 \mathrm{hr}$ (green bars), $10 \mathrm{hr}$ (red bars) and $16 \mathrm{hr}$ (yellow bars), based on spot size and pixel intensity. The relative amount of each protein was determined using the 2D Phoretix software. The protein numbers refer to additional file I.

Some of the secretome proteins have metabolic functions that would typically place them in the cytoplasm. However, 2-DE secretome and cytosol subproteomes show distinct, significantly different patterns from another (Fig. 7). Using MALDI-TOF MS the protein spots in the cytosol were identified, the relative protein spot intensities analyzed, and their ratio to each other determined. These results were used for computer assisted comparison of cytosol and secretome 2-DE gels. Out of the 489 unique

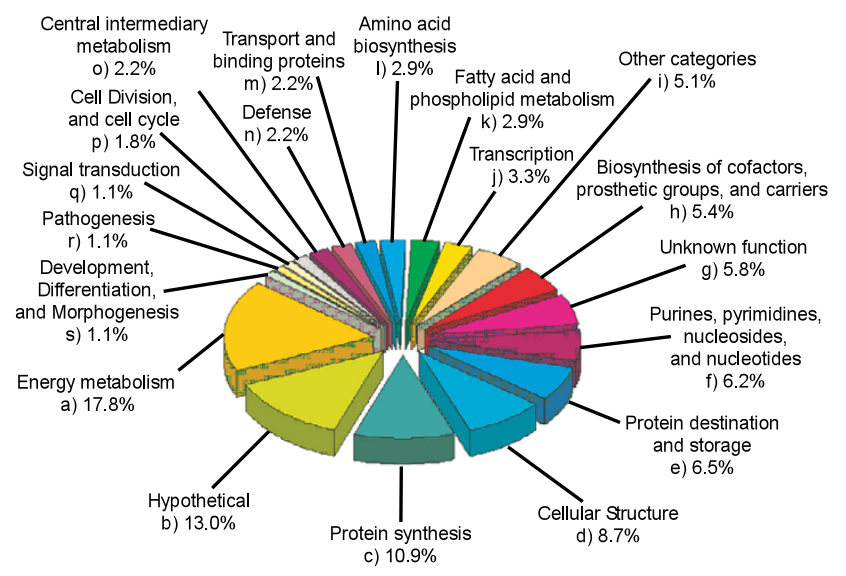

Figure 6

Role category pie chart showing the percentage of all identified $B$. anthracis strain RA3R ( $\mathrm{pXOI} / \mathrm{pXO2-)}$ secretome proteins in each role family. 
protein spots in the cytosol, 56 are more than two-fold up regulated, 84 are more than two-fold down regulated, and 177 proteins spots have no corresponding spot in the secretome (Fig. 7B). If protein spots in the secretome were simply the result of cell lysis, not only should their relative position on the gel be the same between the cytosol and the secretome, but the ratio of the proteins to each other in each subproteome should be the same in both. The results show that two thirds of all protein spot positions as well as relative abundances are distinctively different between the cytosol and secretome. Therefore, cell lysis can be excluded as the major contributor to the protein accumulation in the secretome. The extracellular proteins were further analyzed using various bioinformatics software programs, such as SignalP, SecretomeP, PSORT, LipoP, TMHMM, and PROSITE for predicting protein secretion and localization.

\section{Classical Sec pathway}

A total of 53 proteins were predicted by SignalP to be secreted in the classical Sec pathway, which is characterized by the presence of a signal peptide $[16,17]$ (additional file 1). Of the 53 proteins containing the signal peptides, 38 proteins have the cleavage site for signal peptidase I (SpI). These proteins are predicted to be secreted into the external environment, because they lack additional retention signals. However, 10 proteins have the cleavage site for signal peptidase II (SpII) and the retention signals for lipid anchors while three proteins were predicted to have transmembrane helices (TMH). These proteins are predicted to have an extracytoplasmic but cell-associated location. LipoP predictions discriminate between lipoprotein signal peptides, other signal peptides, and N-terminal membrane helices with 93\% accuracy in Gram positive bacteria [18]. In contrast to LipoP, TMHMM predicted 25 integral membrane proteins with one to ten transmembrane helices [19] (additional file 1). TMHMM predicts transmembrane protein topology with a hidden Markov model with a $98 \%$ accuracy. Additional predictions using PROSITE identified several secreted proteins that are also know to be associated with the bacterial cell wall by S-layer homology domains or lipoprotein lipid attachment sites $[7,20]$. No cell wall associated proteins with LPXTG-motifs were found in the secretome. Despite its name, the LPXTG-motif cell wall anchor domain protein does not contain such a domain. In fact, it contains a NEAT domain that might be involved in the transport of iron.

\section{Alternative Sec pathway}

Twenty-three proteins were predicted by SecretomeP to be secreted by the non-classical Sec Pathway characterized by the lack of typical export signals [21]. In contrast to the predictions of SignalP and SecretomeP, PSORT [22] predicted 171 extracellular proteins, 7 cell wall-associated
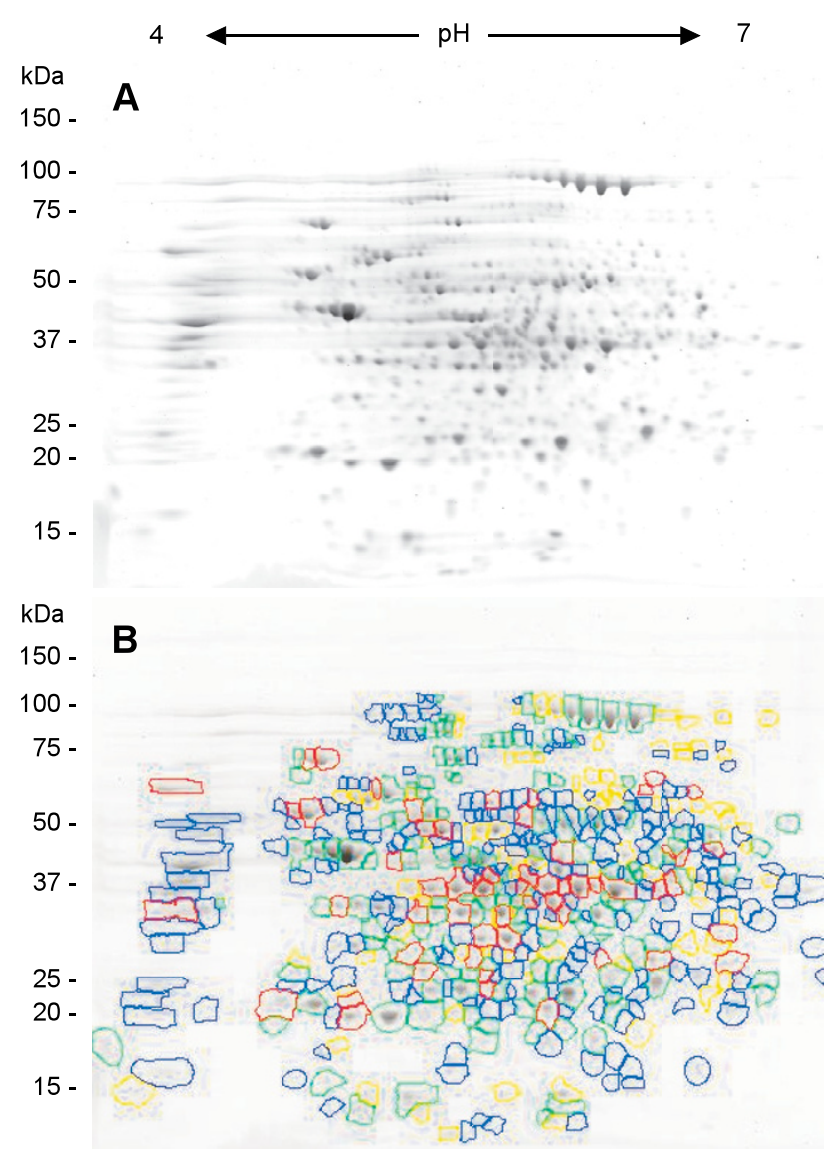

Figure 7

(A) 2-DE gel image of SYPRO Ruby-stained cytosol proteins of toxigenic, non-encapsulated $B$. anthracis strain RA3R (pXOI $/ \mathrm{pXO2-)}$ from $\mathrm{pH} 4$ to 7 at $16 \mathrm{hr}$ under induced conditions. (B) 2D Phoretix comparative analysis of the cytosol with the secretome at $16 \mathrm{hr}$ under induced conditions. Proteins encircled in red are more than two fold up-regulated, proteins encircled in yellow are more than two fold downregulated, proteins encircled in green are between these limits, and proteins encircled in blue are unmatched between the two sub proteomes.

proteins, and 6 cytoplasmic proteins. Using the whole genome of $B$. anthracis, Binnewies et al. have calculated that the Bacillus anthracis Ames strain has 6\% secreted proteins predicted using SecretomeP, 3\% using LipoP, and $6 \%$ using SignalP [23].

\section{Immunogenic extracellular proteins}

The main immunogenic proteins detected by 2-DE Western blot analysis using sera from humans infected with cutaneous anthrax include the 83 and $63 \mathrm{kDa}$ charge variants of protective antigen (PA), followed by charge variants of enolase and transketolase (Fig. 2D). The protective antigen produced in vivo has a molecular mass of $83 \mathrm{kDa}$ 
and is subsequently cleaved by cell-associated protease activity resulting in a $63 \mathrm{kDa}$ protein that binds the lethal factor to form lethal toxin [24]. Notably, 17 charge and mass variants of PA were detected. These include five charge variants of the $83 \mathrm{kDa} \mathrm{PA}$ isoforms, seven charge variants of the $63 \mathrm{kDa} \mathrm{PA}$ isoforms and five charge variants of the $37 \mathrm{kDa} \mathrm{PA}$ isoforms. Charge variants of PA have been reported previously. Their generation was due to the spontaneous deamidation of asparagine residues which is dependent on $\mathrm{pH}$, temperature, primary sequence ("nearest neighbor" effect) and protein conformation [25]. Charge variants of enolase and transketolase were also noted. Enolase has also been reported previously as component of the B. anthracis spore [26] and as one of the immunodominant spore antigens [27]. Other minor immunogenic proteins were also detected by 2-DE Western blot analysis but were not identified.

\section{Discussion}

The secretome of $B$. anthracis has been the subject of recent proteomic studies [6-9]. Interest in its study comes from the fact that several secreted proteins of $B$. anthracis are known virulence factors (e.g., PA, EF, LF). Other secreted proteins may potentially be involved in the adherence of the bacteria to host cells while some may be required for the suppression of the host's defense mechanisms. While several of the virulence proteins have been identified by recent proteomic studies [6,7], the time course of protein secretion by a toxigenic but non-encapsulated strain RA3R (pXO1+/pXO2-) under host simulated conditions has not been reported. In this study, the dynamics of secretion of several proteins were investigated at different time points during the exponential growth phase of $B$. anthracis. The same collection points have been used previously by Lamonica et al. [9] for the isolation of secretome proteins. Chitlaru et al. [6] and Antelmann et al. [7] isolated secretome proteins at analogous growth stages as well. As shown in Fig. 5, the rate of protein secretion varies for each protein. It should be noted that at 6 hours, PA has the highest rate of secretion of all secreted proteins. Since PA is a major component of the anthrax toxin, its high secretion rate at this early time point confirms the critical role this protein plays during the onset of anthrax pathogenesis. Two other proteins that were detected in high abundance in the culture supernatant are the S-layer proteins, EA1 and Sap, both of which are components of the cell wall. Both proteins contain a signal peptide followed by three SLH (S-layer homology) anchoring domains and are considered major surface antigens. The amount of these two proteins was highest at the 16-hour time point compared to the other identified extracellular proteins. It has been previously described that Sap is sequentially replaced by EA1 [28]. This rapid Slayer turnover results in the release and spillover of these proteins into the secretome.
Several of the secretome proteins have metabolic functions that would typically place them in the cytoplasm. This is similar to the results by Antelmann et al. [7] in which more than half of the identified secretome proteins were associated with the cell wall or cytosol. We also identified 25 proteins that were predicted to have transmembrane helices which would typically associate them to the cell wall. All but one of these proteins were predicted to be secreted by SignalP or SecretomeP and half of these proteins have also been identified before as a natural component of the secretome (see additional file 1).

\section{Extracellular accumulation of B. anthracis proteins}

Combined analysis using SignalP and SecretomeP of the B. anthracis secreted proteins indicated that $28 \%$ of the detected proteins are extracellular whereas $62 \%$ are predicted to be extracellular using PSORT. The remaining proteins were predicted to be cytoplasmic since they lacked known export signals or are cell-associated because they have membrane-anchoring or cell wall retention signals. Using LipoP, some of the proteins are predicted to be bound at the trans surface of the cytoplasmic membrane. Contrary to their predicted location, a number of proteins with retention signals for covalent or non-covalent attachment to the cell walls were also found in the extracellular environment.

While bioinformatics tools are useful for predicting cellular function and localization, considerable variation exists in the number of proteins that were predicted to be extracellular, cytoplasmic, or membrane bound. This is expected because each of these bioinformatics tools uses different algorithms and assumptions in their predictions. Further empirical studies are therefore required to verify the precise location of proteins for which conflicting predictions are noted.

\section{Immunogenic extracellular proteins}

The use of sera from human patients infected with cutaneous anthrax confirmed the high immunogenicity of PA in the secreted proteins of the toxigenic but non-encapsulated $B$. anthracis strain RA3R (pXO1+/pXO2-). Although several mass and charge variants of PA were detected, the most immunogenic are the 63 and $83 \mathrm{kDa}$ charge variants. In addition to PA, the major component of AVA (anthrax vaccine adsorbed), enolase and transketolase were found to be highly immunogenic. AVA is an alum precipitate prepared from $B$. anthracis culture filtrates and is a licensed vaccine currently used to protect humans against anthrax. Enolase was also described previously as part of the AVA culture filtrate [29]. AVA preparations contain contaminating proteins whose benefits are not known, but the presence of the highly immunogenic enolase in this formulation might contribute to its protective immunity over a vaccine containing just PA. The membrane pro- 
teins Sap and EA1 were also found in the secretome by Chitlaru et al. [6] and Antelmann et al. [7] as the most abundant extracellular cell wall proteins. Both proteins were reported as major surface antigens and potential vaccine carriers in vivo [30,31]. EA1 and Sap are also major components of AVA [29] and are associated with a variety of functions ranging from evasion of host recognition, cell adhesion and resistance, and phagocytosis [1,32,33]. Interestingly no reactivity to these proteins was observed using sera from patients with subcutaneous anthrax infection. Overall fewer immunogenic proteins were detected using human sera from patients infected with cutaneous anthrax than in a recent study by Chitlaru et al. [30] who used experimentally challenged rabbit and guinea pig sera. There is a quantitative and qualitative difference between sera from recovering humans and sera from multiple challenged animals. Since with human sera enolase and transketolase were major immunogens beside PA, they might be promising candidates for next generation anthrax subunit vaccines besides the newly identified proteins using animal sera [30].

\section{Conclusion}

The work presented here is the first description of the time course of protein secretion for $B$. anthracis grown under host-simulated conditions. The combined use of two types of mass spectroscopy led to the identification of 275 proteins and their secretion patterns during the exponential growth phase of $B$. anthracis. While the secretome contained several predictable proteins (e.g. PA, LF, Sap, and EA1) many proteins were identified which would not be expected in the secretome such as proteins involved in energy metabolism and protein translation. The discovery of proteins in the secretome that are traditionally thought to be strictly cytosolic has often been assumed to result from contamination. However, this may not be true since cytosolic proteins, such as aldolase, enolase, elongation factor $G$, and various dehydrogenases, have also been detected in the secretome of group A streptococci [34], mycobacteria [35,36], and B. subtilis [37]. Some proteins may be cytoplasmic at one point of the cell cycle and secreted via pathways which are yet to be understood during other stages of the cell cycle. While prediction software are a good tool to characterize a large group of proteins, different algorithms give diverging results. It is far more difficult to accurately predict a precise location within a cell of non-classical secretory proteins than to recognize proteins which are secreted by a signal peptide. The ultimate proof is to empirically validate their results. This study helps to bridge the gap between pure in silico prediction and in vivo observation.

This study also identified the major immunoreactive proteins of the B. anthracis secretome using 2-DE Western blot analysis from humans infected with the pathogen.
These proteins included the expected PA as well as enolase and transkelolase. The immunoreactive secretome proteins contribute to the list of other $B$. anthracis immunogenic proteins that were idenfied in other subproteomes or life-stages of the infectious agent. This knowledge will ultimately lead to the development of a more-specific, safer, and highly efficacious vaccine against $B$. anthracis. In addition, the identification of early high abundance secretome proteins may aid in the development of detection and diagnostic kits for those cases, where the direct capture of the pathogen is not possible.

\section{Methods}

\section{Bacterial strain and culture conditions}

An attenuated derivative strain of $B$. anthracis, RA3R (pXO1+/pXO2-), was used. A loop was streaked on BHI agar overnight $(16 \mathrm{hr})$ at $37^{\circ} \mathrm{C}$. A single colony was transferred to $2 \mathrm{ml} \mathrm{R}$ medium [4] and approximately $1 \mathrm{ml}$ of the resulting suspension was immediately transferred in $100 \mathrm{ml} \mathrm{R}$ medium supplemented with $0.25 \%$ [wt/vol] glucose. The flask was mixed gently and fitted with a BugStopper (Whatman Inc., Clifton, NJ) sterile venting closure. The culture was incubated at $37^{\circ} \mathrm{C}$ with shaking at $120 \mathrm{rpm}$ for 5 to $6 \mathrm{hr}$. Following this growth period, $5 \mathrm{ml}$ of the culture was transferred to a $250-\mathrm{ml}$ sterile, vented, canted Falcon tissue culture flask containing $70 \mathrm{ml} \mathrm{R}$ medium with $0.25 \%$ [wt/vol] glucose and $0.85 \%$ [wt/vol] sodium bicarbonate. The composition of the R-medium in $\mathrm{mg} / \mathrm{l}$ is: L-tryptophan, 35; glycine, 65; L-cystine, 25; Ltyrosine, 144; L-lysine, 230; L-valine, 173; L-leucine, 230; L-isoleucine, 170; L-threonine, 120; L-methionine, 73; Laspartic acid, 184; sodium L-glutamate, 612; L-proline, 43; L-histidine-hydrochloride, 55; L-arginine-hydrochloride, 125; L-phenylalanine, 125; L-serine, 235; thiaminehydrochloride, 1.0; $\mathrm{CaCl}_{2} 2 \mathrm{H}_{2} \mathrm{O}, 7.4 ; \mathrm{MgSO}_{4} \mathrm{H}_{2} 0$, 9.9; $\mathrm{MnSO}_{4} \mathrm{H}_{2} 0,0.9 ; \mathrm{K}_{2} \mathrm{HPO}_{4}, 3,000$; uracil, 1.4; and adenine sulfate, 2.1, pH 8.0. The culture was grown for 6 to $16 \mathrm{hr}$ at $37^{\circ} \mathrm{C}$ under $5 \% \mathrm{CO}_{2}$ in a humid incubator according to Ristroph et al. [4] to simulate conditions encountered in the host. The $\mathrm{pH}$ at the end of the incubation period rises to $\mathrm{pH}$ 8.15. During this time the cells are in the exponential growth phase, between lag- and stationary- phase. Uninduced cultures were grown in $\mathrm{R}$ medium without the addition of sodium bicarbonate and without $\mathrm{CO}_{2}$ supplementation.

\section{Preparation of extracellular protein fraction}

Culture filtrates (secretomes) were collected at $6 \mathrm{hr}$ (early log phase), $10 \mathrm{hr}$ (mid log phase), and $16 \mathrm{hr}$ (late log phase) time points based on the growth curve for $B$. anthracis in $\mathrm{R}$ medium, as determined by $\mathrm{OD}_{595}$ readings. The culture filtrates were centrifuged for $10 \mathrm{~min}$ and the supernatant containing the extracellular proteins was passed through a $0.45-\mu \mathrm{m}$ filter to remove any suspended vegetative cells. The culture filtrates were concentrated 
using Jumbosep, Macrosep, and Microsep filters with a 10 kDa cutoff (Pall Inc., East Hills, NY). Ice-cold trichloroacetic acid (TCA; Sigma Chemical Co., St. Louis, MO) was then added to a final concentration of 10\% TCA (vol/vol), chilled on ice for $45 \mathrm{~min}$, and then centrifuged for $45 \mathrm{~min}$. The resultant pellet was washed with $3 \mathrm{ml}$ acetone and centrifuged. The pellet containing the secretome proteins was resuspended in $100 \mu \mathrm{l}$ of $7 \mathrm{M}$ urea, $2 \mathrm{M}$ thiourea, 1\% 3-(4-heptyl)phenyl-3-hydroxypropyl-dimethylammoniopropanesulfonate, and $40 \mathrm{mM}$ Tris prior to IEF. The protein concentration of the extracellular protein extract was determined using the Bio-Rad Protein Assay kit (Bio-Rad Laboratories, Hercules, CA). Bovine serum albumin was used as the standard for determination of protein concentration.

\section{2-DE and Western blot analysis}

2-DE was carried out with the ElectrophoretIQ3 system and following the manufacturer's protocols (Proteome Systems, Woburn, MA). One-hundred $\mu$ g of proteins were separated by IEF on $11 \mathrm{~cm}$ (pH 4 to 7 ) linear IPG strips. After 12 hr rehydration, the following focusing parameters were applied: $50 \mu \mathrm{A}$ per strip, linear voltage increase over $8 \mathrm{hr}$ from $100 \mathrm{~V}$ to $10,000 \mathrm{~V}$, and then held at 10,000 $\mathrm{V}$ for $10 \mathrm{hr}$. After IEF, IPG strips were equilibrated in equilibration buffer and applied onto a $6-15 \%$ gradient SDSPAGE. Gels were electrophoresed for $1.5 \mathrm{hr}$ at $500 \mathrm{~V}$ and stained with Sypro Ruby (Sigma-Aldrich, St. Louis, MO) for gel analysis or with ProteomIQ Blue (Proteome Systems) for MALDI-TOF MS analysis. Four replicate 2-DE gels of each sample were used for computer analysis using Phoretix 2D Expression software (Nonlinear Dynamics) and MALDI-TOF MS. Following automatic spot detection on quadruple gels using Phoretix 2D Expression's detection algorithm, gels were manually warped and their common spots were matched to generate average gels.

Immunoblotting was conducted according to Towbin et al. [38]. Proteins on 2-DE gels were transferred to PVDF membranes using Towbin buffer $(0.025 \mathrm{M}$ trisma base in $0.192 \mathrm{M}$ glycine) with $20 \%$ methanol at $100 \mathrm{~V}$ for $30 \mathrm{~min}$. After transfer, the PVDF membrane was washed twice for 5 min each in 0.01\% Tween-20 in PBS (PBST) and blocked with 0.2\% I-Block (Tropix, Bedford, MA) for $1 \mathrm{hr}$. To identify immunogenic proteins, the PVDF membranes were washed three times with PBST for $5 \mathrm{~min}$ and then probed with a 1:1000 dilution of sera pooled from patients who recovered from cutaneous anthrax. The PVDF membrane was washed three times with PBST and incubated with 1:5000 dilution of appropriate secondary antibody. Chemiluminescent signals were visualized using the Western Lightning reagents (Perkin-Elmer, Wellesley, MA). Corresponding sera from uninfected humans were used as controls (Cambrex, Charles City, IA). Three replicate blots were used for computer analysis using the Phoretix 2D Expression software to identify the immunogenic proteins.

\section{In-gel trypsin digestion and MALDI-TOF MS}

Protein spots were excised, washed, and trypsin digested from 2-DE gels according to manufacturer's instructions using the Xcise robotic workstation (Shimadzu Biotech, Columbia, MD). Briefly, gel plugs were washed with 50 $\mathrm{mM}$ ammonium bicarbonate and 50\% acetonitrile $(\mathrm{ACN})$, dried, and treated with $1.6 \mu \mathrm{g} / \mathrm{ml}$ of trypsin in 50 $\mathrm{mM}$ ammonium bicarbonate at $37^{\circ} \mathrm{C}$ overnight. Tryptic peptides were applied to a MALDI-TOF MS plate in a solution of $10 \mathrm{mg} / \mathrm{ml}$ alpha-cyano-4-hydroxycinnamic acid in $0.1 \%$ trifluoroacetic acid and 50\% ACN. MS spectra were obtained using an Axima-CFR plus (Shimadzu Biotech) in a positive ion reflectron mode and analyzed against the theoretical spectra of $B$. anthracis strain Ames, using the Mascot Daemon software package (Matrix Science, Boston, MA). The search parameters were: maximum of one missed cleavage by trypsin, fixed modification of oxidation, charged state of +1 , and mass tolerance of $\pm 0.5 \mathrm{Da}$.

\section{Protein identification by LC MSIMS}

All LC MS/MS analyses were performed using an Agilent 1100 nanopump system coupled with a Vydac C18 reverse phase column $(75 \mu \mathrm{M})$ (Agilent, Santa Clara, CA) and a QTRAP 2000 LC MS/MS system (Applied Biosystems, Foster City, CA) outfitted with a nanospray source and controlled with Analyst 1.4.1 software. Proteins were prepared for digestion using heat denaturation and a modified organic-aqueous digestion method as described before [14]. Each digested and desalted sample was re-suspended in $10 \mu \mathrm{l}$ of Buffer A (95\% water, 5\% ACN, 0.1\% formic acid). Each sample $(7 \mu \mathrm{l})$ was loaded onto the LC $\mathrm{MS} / \mathrm{MS}$ system and analyzed using an independent data acquisition method with the following parameters: single enhanced mass spectra (EMS, 500-1500 m/z) from which the three most intense peaks were subjected to an enhanced resolution, from which ions with a charge state of +2 to +4 were subjected to an enhanced product ion [EPI (MS/MS)] scan. Once the three most intense peaks were subjected to downstream analysis, they were ignored for a period of $60 \mathrm{sec}$. LC gradient was 5-60\% Buffer B (95\% ACN, 5\% water, $0.1 \%$ formic acid) over $35 \mathrm{~min}$. General parameter settings are as follows (curtain gas: 15.00, collision gas: High, ion spray: $2200 \mathrm{v}$, interface heater: on, declustering potential: 30 , entrance potential: 10, collision energy: 10, rolling collision energy). All MS/ MS data were searched against the theoretical spectra of $B$. anthracis Ames using the MASCOT software (Matrix Science). The search parameters used were: maximum of one missed cleavage by trypsin, fixed modification of oxidized methionine, charge state of +2 and +3 , an MS tolerance of $\pm 1.2 \mathrm{Da}$ and an MS/MS tolerance of $\pm 0.8 \mathrm{Da}$. Only 
protein identifications that met or exceeded the minimal MOWSE score of 22 were included in additional file 1.

\section{Abbreviations}

2-DE: two-dimension gel electrophoresis

ACN: acetonitrile

EF: edema factor

IEF: isoelectric focusing

LC: liquid chromatography

LF: lethal factor

MALDI-TOF: matrix assisted laser desorption/ionization time of flight

MS: mass spectrometry

MS/MS: tandem mass spectrometry

PA: protective antigen

SLH S-layer homology

\section{Competing interests}

The author(s) declare that they have no competing interests.

\section{Authors' contributions}

AW carried out the secretome preparation, data analysis, conceived the study, and helped drafting the manuscript. CVM drafted the manuscript and participated in design of the study. JPC and TA performed the MALDI-TOF and LC MS/MS analysis. RC performed the 2D Phoretix comparative analysis. CD and JW performed the $2 \mathrm{D}$ gel electrophoresis and Western blotting. SPK and ASK participated in the design of the study, and VGD participated in the design of the study and helped to draft the manuscript. All authors read and approved the final manuscript.

\section{Additional material}

\section{Additional file 1}

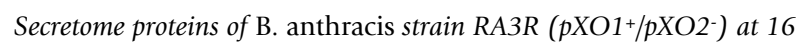
$h r$, as identified by MALDI-TOF and LC MS/MS

Click here for file

[http://www.biomedcentral.com/content/supplementary/14775956-5-11-S1.xls]

\section{Acknowledgements}

We thank Dr. Xudong Liang of the University of Minnesota for the gift of the sera from patients infected with cutaneous anthrax. Thisresearch was supported bya contract with the US Army RDECOM ACQ CTR (\#W9I INF-05-C-0047) as part of the BioSPICE initiative.

\section{References}

I. Mock M, Fouet A: Anthrax. Annu Rev Microbiol 200I, 55:647-67I.

2. Makino S, Uchida I, Terakado N, Sasakawa C, Yoshikawa M: Molecular characterization and protein analysis of the cap region, which is essential for encapsulation in Bacillus anthracis. J Bacteriol 1989, I 1 1:722-730.

3. Uchida I, Makino S, Sasakawa C, Yoshikawa M, Sugimoto C, Terakado $\mathrm{N}$ : Identification of a novel gene, dep, associated with depolymerization of the capsular polymer in Bacillus anthracis. Mol Microbiol 1993, 9:487-496.

4. Ristroph JD, Ivins BE: Elaboration of Bacillus anthracis antigens in a new, defined culture medium. Infect Immun 1983, 39:483-486

5. Sirard JC, Mock M, Fouet A: The three Bacillus anthracis toxin genes are coordinately regulated by bicarbonate and temperature. J Bacteriol 1994, I76:5 I88-5192.

6. Chitlaru T, Gat O, Gozlan Y, Ariel N, Shafferman A: Differential proteomic analysis of the Bacillus anthracis secretome: distinct plasmid and chromosome CO2-dependent cross talk mechanisms modulate extracellular proteolytic activities. J Bacteriol 2006, 188:355I-357I.

7. Antelmann H, Williams RC, Miethke M, Wipat A, Albrecht D, Harwood $C R$, Hecker M: The extracellular and cytoplasmic proteomes of the non-virulent Bacillus anthracis strain UM23CI2. Proteomics 2005, 5:3684-3695.

8. Gohar M, Gilois N, Graveline R, Garreau C, Sanchis V, Lereclus D: A comparative study of Bacillus cereus, Bacillus thuringiensis and Bacillus anthracis extracellular proteomes. Proteomics 2005, 5:3696-37II.

9. Lamonica JM, Wagner M, Eschenbrenner M, Williams LE, Miller TL, Patra G, Delvecchio VG: Comparative secretome analyses of three Bacillus anthracis strains with variant plasmid contents. Infect Immun 2005, 73:3646-3658.

10. Gohar M, Okstad OA, Gilois N, Sanchis V, Kolsto AB, Lereclus D: Two-dimensional electrophoresis analysis of the extracellular proteome of Bacillus cereus reveals the importance of the PIcR regulon. Proteomics 2002, 2:784-79I.

II. Agaisse H, Gominet M, Okstad OA, Kolsto AB, Lereclus D: PIcR is a pleiotropic regulator of extracellular virulence factor gene expression in Bacillus thuringiensis. Mol Microbiol 1999 , 32:1043-1053.

12. Mignot T, Mock M, Robichon D, Landier A, Lereclus D, Fouet A: The incompatibility between the PIcR- and AtxA-controlled regulons may have selected a nonsense mutation in Bacillus anthracis. Mol Microbiol 200 I, 42:1 I89-II 98.

13. Schmidt F, Donahoe S, Hagens K, Mattow J, Schaible UE, Kaufmann $\mathrm{SH}$, Aebersold R, Jungblut PR: Complementary analysis of the Mycobacterium tuberculosis proteome by two-dimensional electrophoresis and isotope-coded affinity tag technology. Mol Cell Proteomics 2004, 3:24-42.

14. Connolly JP, Comerci D, Alefantis TG, Walz A, Quan M, Chafin R, Grewal P, Mujer CV, Ugalde RA, Delvecchio VG: Proteomic analysis of Brucella abortus cell envelope and identification of immunogenic candidate proteins for vaccine development. Proteomics 2006, 6:3767-3780.

15. The Institute for Genomic Research 2007 [http://www.tigr.org].

16. Bendtsen JD, Nielsen H, Von HG, Brunak S: Improved prediction of signal peptides: SignalP 3.0. J Mol Biol 2004, 340:783-795.

17. Nielsen H, Engelbrecht J, Brunak S, Von HG: Identification of prokaryotic and eukaryotic signal peptides and prediction of their cleavage sites. Protein Eng 1997, 10:1-6.

18. Juncker AS, Willenbrock H, Von HG, Brunak S, Nielsen $H$, Krogh A: Prediction of lipoprotein signal peptides in Gram-negative bacteria. Protein Sci 2003, I 2:1652-1662.

19. Krogh A, Larsson B, Von HG, Sonnhammer EL: Predicting transmembrane protein topology with a hidden Markov model: application to complete genomes. J Mol Biol 200I, 305:567-580. 
20. Hulo N, Bairoch A, Bulliard V, Cerutti L, de CE, Langendijk-Genevaux PS, Pagni M, Sigrist CJ: The PROSITE database. Nucleic Acids Res 2006, 34:D227-D230.

2I. Bendtsen JD, Jensen LJ, Blom N, Von HG, Brunak S: Feature-based prediction of non-classical and leaderless protein secretion. Protein Eng Des Sel 2004, I 7:349-356.

22. Nakai K, Horton P: PSORT: a program for detecting sorting signals in proteins and predicting their subcellular localization. Trends Biochem Sci 1999, 24:34-36.

23. Binnewies TT, Bendtsen JD, Hallin PF, Nielsen N, Wassenaar TM, Pedersen MB, Klemm P, Ussery DW: Genome Update: Protein secretion systems in $\mathbf{2 2 5}$ bacterial genomes. Microbiology 2005 151:1013-1016.

24. Ezzell JW Jr., Abshire TG: Serum protease cleavage of Bacillus anthracis protective antigen. I Gen Microbiol 1992, I 38:543-549.

25. Zomber G, Reuveny S, Garti N, Shafferman A, Elhanany E: Effects of spontaneous deamidation on the cytotoxic activity of the Bacillus anthracis protective antigen. I Biol Chem 2005, 280:39897-39906.

26. Liu H, Bergman NH, Thomason B, Shallom S, Hazen A, Crossno J, Rasko DA, Ravel J, Read TD, Peterson SN, Yates J III, Hanna PC: Formation and composition of the Bacillus anthracis endospore. J Bacteriol 2004, I 86: I 64- I78.

27. Delvecchio VG, Connolly JP, Alefantis TG, Walz A, Quan MA, Patra G, Ashton JM, Whittington JT, Chafin RD, Liang X, Grewal P, Khan AS, Mujer CV: Proteomic profiling and identification of immunodominant spore antigens of Bacillus anthracis, Bacillus cereus, and Bacillus thuringiensis. Appl Environ Microbiol 2006 , 72:6355-6363.

28. Mignot T, Mesnage S, Couture-Tosi E, Mock M, Fouet A: Developmental switch of S-layer protein synthesis in Bacillus anthracis. Mol Microbiol 2002, 43:1615-1627.

29. Whiting GC, Rijpkema S, Adams T, Corbel MJ: Characterisation of adsorbed anthrax vaccine by two-dimensional gel electrophoresis. Vaccine 2004, 22:4245-425I.

30. Chitlaru T, Gat O, Grosfeld H, Inbar I, Gozlan Y, Shafferman A: Identification of In Vivo-Expressed Immunogenic Proteins by Serological Proteome Analysis of the Bacillus anthracis Secretome. Infect Immun 2007, 75:284 I-2852

31. Chitlaru T, Ariel N, Zvi A, Lion M, Velan B, Shafferman A, Elhanany E. Identification of chromosomally encoded membranal polypeptides of Bacillus anthracis by a proteomic analysis: prevalence of proteins containing S-layer homology domains. Proteomics 2004, 4:677-69l.

32. Mesnage S, Tosi-Couture E, Mock M, Fouet A: The S-layer homology domain as a means for anchoring heterologous proteins on the cell surface of Bacillus anthracis. J Appl Microbiol 1999, 87:256-260.

33. Sara M, Sleytr UB: S-Layer proteins. J Bacteriol 2000, I 82:859-868.

34. Lei B, Mackie S, Lukomski S, Musser JM: Identification and immunogenicity of group A Streptococcus culture supernatant proteins. Infect Immun 2000, 68:6807-68I8.

35. Jungblut PR, Schaible UE, Mollenkopf HJ, Zimny-Arndt U, Raupach B, Mattow J, Halada P, Lamer S, Hagens K, Kaufmann SH: Comparative proteome analysis of Mycobacterium tuberculosis and Mycobacterium bovis BCG strains: towards functional genomics of microbial pathogens. Mol Microbiol 1999, 33: I I03-I I I7.

36. Rosenkrands I, Weldingh K, Jacobsen S, Hansen CV, Florio W, Gianetri I, Andersen P: Mapping and identification of Mycobacterium tuberculosis proteins by two-dimensional gel electrophoresis, microsequencing and immunodetection. Electrophoresis 2000, 21:935-948.

37. Antelmann H, Tjalsma H, Voigt B, Ohlmeier S, Bron S, van Dijl JM, Hecker M: A proteomic view on genome-based signal peptide predictions. Genome Res 200 I, I I:|484-| 502.

38. Towbin H, Staehelin T, Gordon J: Electrophoretic transfer of proteins from polyacrylamide gels to nitrocellulose sheets: procedure and some applications. Proc Natl Acad Sci U S A 1979, 76:4350-4354
Publish with Bio Med Central and every scientist can read your work free of charge

"BioMed Central will be the most significant development for disseminating the results of biomedical research in our lifetime. "

Sir Paul Nurse, Cancer Research UK

Your research papers will be:

- available free of charge to the entire biomedical community

- peer reviewed and published immediately upon acceptance

- cited in PubMed and archived on PubMed Central

- yours - you keep the copyright

Submit your manuscript here:

http://www.biomedcentral.com/info/publishing_adv.asp
BioMedcentral 